RIBEIRO, Ana Elisa. Escrever, hoje: palavra, imagem e tecnologias digitais na educação. São Paulo: Parábola, 2018. $128 \mathrm{p}$.

\title{
Escrita, multimodalidade e ensino: teoria e prática
}

\author{
Heloísa Queiroz*
}

Ao voltar nosso olhar para uma abordagem educacional tradicional, muitas vezes, são considerados como material de aprendizagem da leitura e da escrita apenas textos com a linguagem verbal, colocando em uma hierarquia a escrita em detrimento de outros modos linguísticos de comunicação, como a oralidade, as imagens, os vídeos, gestos e expressões faciais. Com o passar dos anos e com o advento das novas tecnologias - que não são mais tão novas assim —, na vida prática das pessoas, destacando-se atualmente as redes sociais, a escola passou, diversas vezes, a andar em descompasso com o mundo da vida, uma vez que a educação tradicional proíbe, por exemplo, o uso de telefones ou outras tecnologias em sala de aula, sem refletir sobre essa proibição. Ao analisar o modo de ensinar a ler e a escrever hoje, é necessário rever as práticas educacionais e atentar-se para a multimodalidade que, por sua vez, amplia a necessidade de trabalhar novas habilidades de escrita e leitura com os estudantes. Entretanto, como trabalhar essas habilidades? As reflexões que surgem a partir das respostas para essa pergunta estão apresentadas no livro de Ribeiro (2018), com foco principal no processo da escrita.

\footnotetext{
* Pontifícia Universidade Católica de Minas Gerais (PUC Minas). Mestre em Linguística e Língua Portuguesa pela Pontifícia Universidade Católica de Minas Gerais. Doutoranda em Linguística e Língua Portuguesa e bolsista do CNPq. ORCID: 0000$0002-9632-8590$
} 
A autora Ana Elisa Ribeiro é professora do Centro Federal de Educação Tecnológica de Minas Gerais, onde atua no Ensino Técnico, na Graduação e no Programa de Pós-Graduação em Estudos da Linguagem. Ela é doutora em Linguística Aplicada pela UFMG, autora de diversas publicações sobre leitura, escrita, edição e as relações desses temas com as tecnologias. É também uma autora com diferentes publicações na área da literatura e, vale ressaltar, indicada ao Prêmio Jabuti 2020 com o livro Dicionário de imprecisões - Editora Impressões de Minas, leitura realmente imperdível.

O livro Escrever, hoje: palavra, imagem e tecnologias digitais na educação, publicado em 2018, possui nove capítulos, sendo o primeiro um prefácio escrito pela professora Carla Coscarelli (UFMG) e o nono uma conclusão que aponta para novos começos. A autora considera a escrita como um processo social e historicamente situado e que, portanto, acompanha as diversas mudanças existentes, fazendo com que as tecnologias digitais de que dispomos atualmente sejam mais uma fase dessa mudança e não uma competição com os métodos de escrever anteriores às tecnologias digitais.

No capítulo (ii), intitulado "Cultura escrita, cultura impressa, cultura digital: contiguidades e tensões", a autora faz um breve panorama de como a escrita esteve presente na sociedade e como ela se deu de forma diferente em variadas culturas. Além disso, Ribeiro (2018) ressalta a diferença entre a cultura escrita, que era manuscrita e coocorria com a cultura oral, e a cultura impressa, que só surgiu a partir da prensa. Porém, uma cultura não anulou a outra, mas elas continuaram ocorrendo em práticas distintas, assim como, com o surgimento das tecnologias digitais, houve o acréscimo da cultura digital, ampliando as possibilidades ao 
escrever. A autora, então, inicia uma discussão sobre o conceito de cibercultura, trazendo a voz do filósofo Pierre Lévy (1999) e dos autores brasileiros Santaella (2003), Lemos (2002; 2004), Pretto (2010), Felinto (2006) e Soares (2002), deixando claro que há não só uma tensão entre os olhares que se voltam para as diferentes culturas aqui apresentadas, mas também um rico momento de transição que possibilita diversos estudos. Para ilustrar as tensões, Ribeiro (2018) cita exemplos práticos, por ela vivenciados, em uma biblioteca, com a chegada dos telecentros e em um processo de editoração de uma obra, com os impasses das questões autorais advindos das possibilidades digitais.

No capítulo (iii), intitulado "Nunca mais vejo um jornal do mesmo jeito - relações entre leitura, edição e letramento", a autora discute o conceito de letramento já abordado por Soares (2004), destacando que as práticas de leitura e escrita estão se tornando, cada vez mais, sofisticadas na sociedade atual e que devemos, inclusive, considerar os estudos da edição no conceito de letramento. A partir dessa visão, Ribeiro (2018) demonstra a importância de os leitores terem consciência "da existência de processos de edição e das consequências trazidas para o livro que lemos, o jornal que temos o hábito de ler ou de assistir e assim por diante" (RIBEIRO, 2018, p. 31), já que a edição pode trazer um recorte ou um enquadramento maior em determinada parte de um texto e não em outra, provocando diferentes leituras de um mesmo fato a depender do que é mostrado. A autora demonstra exemplos práticos de diferentes escolhas de capas de jornais para noticiar um mesmo fato e leva o leitor a perceber que, entendendo os processos — nada neutros — de escolha que constroem os textos, nenhum leitor lê um jornal do mesmo jeito que leria antes de ter consciência desses processos. 
No capítulo (iv), intitulado "Como centenas de "nativos digitais' leem 'ícones'”, Ribeiro (2018) apresenta a conceituação de Prensky (2001) sobre nativos digitais (nascidos após a popularização do computador e das redes) e imigrantes digitais (nascidos antes dessa popularização) e destaca inúmeros estudos que se valem dessa conceituação para a reforçar, completar ou criticar. Nesse contexto, a autora admite que, como pesquisadora, filia-se à linha de pesquisa que critica essa conceituação — nativos digitais e imigrantes digitais, uma vez que considera também o interesse dos jovens e os impactos dos fatores socioeconômicos e culturais. Ribeiro (2018) apresenta-nos uma pesquisa feita com 250 jovens, que seriam considerados "nativos digitais", sobre os comandos existentes nos programas Word e Power Point. Com essa pesquisa, surge um interessante resultado, que nos permite refletir sobre o que Peirce (2000) chama de "ícone" e a transformação deste em símbolo, com o passar dos anos, para a experiência dos leitores e sobre a necessidade de investir em letramentos na cultura impressa escrita e digital.

No capítulo (v), intitulado "Palavra \& criação, palavra e ação: livro, leitura e escrita em pauta", a autora faz uma interessante discussão sobre o processo de criação do texto escrito. Nela é construída uma metáfora, a qual diz que, assim como o escultor precisa se atentar ao material utilizado e demais fatores que podem influenciar sua escultura, aquele que escreve precisa lidar com a palavra e com tudo o que ela não diz e, além disso, com todos os fatores que podem cercar aquele texto. Ademais, para talvez alcançar os não ditos, discute sobre a relação entre palavra e imagem, permitindo-nos perceber a necessidade de também aprender a ler imagens, assim como lemos palavras, mas que "as dinâmicas e sintaxes gramáticas dessas linguagens 
são diferentes". (RIBEIRO, 2018, p. 67). Ribeiro (2018) ainda discute o conceito de palavra, de texto e de livro, demonstrando que não há consenso entre os mais diversos campos de estudo, suscitando nos leitores diversos questionamentos sobre o ato de analisar processos de criação e não se deter apenas à análise dos produtos.

No capítulo (vi), intitulado "Tecnologias na educação: questões e desafios para a produção de sentidos", a autora começa ressaltando a importância de adequar as tecnologias aos objetivos do ensino-aprendizagem, utilizando imagens, sons e demais recursos disponíveis para "sairmos do dizer o mundo para o mostrar o mundo". (KRESS, 2003, p. 140). Para isso, a autora defende o uso da multimodalidade, sem considerar uma modalidade melhor do que outra, mas compreendendo o resultado da interação entre elas, para que, assim, haja uma mudança de paradigma, por exemplo, na sala de aula, e não apenas uma mudança na ferramenta utilizada. Ribeiro (2018) ainda discute, neste capítulo, que aprender não é papel apenas do aluno, mas também do professor, que precisa ser letrado nas práticas digitais para utilizar a multimodalidade como forma de enriquecimento das aulas e como apresentação de possibilidades para os alunos, sempre estando atento aos seguintes questionamentos: quais modalidades usar, se elas fazem sentido/diferença naquele contexto e se são realmente relevantes.

No capítulo (vii), “Tecnologia e poder semiótico: escrever, hoje", a autora introduz a seção fazendo uma autorreflexão sobre o processo de escrita do capítulo, que era um chat, foi modificado inicialmente para se tornar um artigo e mudado novamente nos moldes de um capítulo de livro. Essas alterações foram necessárias a depender de onde o texto circularia, e a autora deixa claro que 
sua opção é "por manter a simplicidade da linguagem, desejando a sensação de proximidade com o leitor". (RIBEIRO, 2018, p. 82). Realmente, a verticalização proposta pela autora em cada capítulo é muito acessível aos leitores devido a seu modo de escrever. Ribeiro (2018), ainda neste capítulo, discute sobre o "poder semiótico", expressão criada por Kress (2003), que seria "o nosso poder de lidar com signos, produzir sentido, manejar linguagens, mais que apenas palavras, inclusive, tanto para ler quanto para escrever" (RIBEIRO, 2018, p. 83), e como esse "poder" é utilizado na escrita. A autora cria, então, uma seção para tratar especificamente da escrita de redações escolares, trazendo uma interessante discussão crítica sobre a redação do Enem e um exemplo prático sobre o ensino da escrita de textos reguladores (desde o planejamento dos textos por parte dos alunos, até o resultado final com as estratégias utilizadas para alcançar o objetivo proposto). Ribeiro (2018) finaliza o capítulo com uma importante reflexão: acima desse "poder semiótico", há a necessidade daquele que escreve de saber lidar com esse "poder", de saber utilizar, para o que necessita, cada uma das modalidades disponíveis.

No capítulo (viii), intitulado "Tecnologia digital e ensino: breve histórico e seis elementos para a ação", a autora faz um breve histórico da inserção das tecnologias nas práticas sociais, desde 1995, com o início da popularização das tecnologias digitais no Brasil, que evoluíram e se inseriram, cada vez mais, no dia a dia das pessoas. Com isso, inúmeros estudos na academia surgiram, demonstrando como as tecnologias digitais poderiam/podem alterar/influenciar/contribuir com o ensino. Porém, Ribeiro (2018) afirma que, mesmo imersa nas tecnologias digitais na sociedade, a escola parece estar em descompasso com 
essa imersão, já que continua "sendo pressionada a fazer algo que ocorre muito mais fluidamente fora de seus muros - que, a propósito, continuam lá” (RIBEIRO, 2018, p. 101), já que a integração tão almejada entre escola e tecnologias digitais não aconteceu plenamente.

A autora propõe uma reflexão sobre a prática docente: por que, mesmo imersos na cultura digital, utilizando as tecnologias digitais rotineiramente fora da escola, os professores — ou a maioria deles — não inserem essas tecnologias como ferramentas para o ensino-aprendizagem? Mesmo com tantas pesquisas voltadas para o tema, qual seria a dificuldade em inserir as tecnologias digitais dentro dos muros escolares? Para responder a essas perguntas, a autora afasta-se da ideia de que os professores seriam incapazes de utilizar ou planejar aulas com o uso das novas tecnologias e volta-se para a apresentação de possibilidades de usos na prática escolar. De forma didática e prática, Ribeiro (2018) apresenta "seis elementos para se pensar e agir nas aulas" (RIBEIRO, 2018, p. 107), para que professores possam refletir e adaptar suas aulas, incluindo elementos das tecnologias digitais para ampliar o leque de possibilidades. Para a reflexão, Ribeiro (2018) propõe as seguintes ações: 1 . Ter vontade de aprender sobre os usos das tecnologias; 2. Usar para saber como as tecnologias funcionam na prática e não apenas na teoria; 3. Relacionar os objetivos de cada aula com algum novo modo de ensinar, utilizando tecnologias digitais; 4. Experimentar, fazendo uma dinâmica de testes que possibilite perceber quais tecnologias funcionam ou não em cada atividade; 5. Avaliar o que já foi feito para manter, readequar ou mudar o modo de fazer e 6. Haver uma boa gestão do tempo de trabalho, e, para que não haja sobrecarga, é preciso o estabelecimento 
de limites. Cada um desses seis tópicos é bem explorado e esclarecido, com a finalidade de o professor refletir a respeito de suas práticas e adequar a realidade de cada prática docente.

Em "Finalizar, por enquanto", título do capítulo (ix), a autora desenvolve a conclusão do livro, apontando para as inconclusões e reflexões que os capítulos anteriores suscitaram e para a importância de estudos e pesquisas teóricas sobre a escrita que contribuam na prática, já que "escrita é poder" (RIBEIRO, 2018, p. 118), e de inserir a prática na teoria, para que os estudos sejam realmente relevantes. Ribeiro (2018) deixa claro que "escrever, hoje", expressão que dá nome ao livro, "é ter a chance de manejar mais ferramentas para ampliar formas de expressão" (RIBEIRO, 2018, p. 97) e utilizar a multimodalidade e o "poder semiótico" é um importante potencializador da escrita de textos na atualidade.

Sem dúvida, pode-se recomendar a leitura deste livro não só para professores que atuam em sala de aula, mas também para aqueles que são interessados e estudiosos da linguagem, seja por causa das interessantes reflexões trazidas sobre escrita, multimodalidade e semiótica, seja pela aplicabilidade das teorias apresentadas em salas de aulas reais, demonstrando a teoria na prática. Além disso, a escrita fluida da autora, as vozes teóricas que se encontram no texto e os relatos de resultados da teoria aplicada em salas de aulas reais formam uma obra profunda e, ao mesmo tempo, leve para ser lida, deixando os leitores com inúmeras reflexões e com inspirações para novos estudos que também possam contribuir significativamente com a escrita, hoje.

Recebido em 19/04/2021 // Aceito em: 22/04/2021 


\section{Referências}

FELINTO, Érick. Os computadores também sonham? Para uma teoria da cibercultura como imaginário. Intexto, [s. l.], v. 2, n. 15, dez. 2006.

KRESS, Gunther. Literacy in the New Media Age. London (New York): Routledge, 2003.

LEMOS, André. Cibercultura, cultura e identidade. Em direção a uma "cultura copyleft"?. Contemporânea, [s. l.], v. 2, n. 2, dez. 2004.

LEMOS, André. Ciber-cultura-remix. Educação e Sociedade, [s. l.], v. 23, n. 81, dez. 2002.

LÉVY, Pierre. Cibercultura. São Paulo: Editora 34, 1999.

PEIRCE, Charles Sanders. Semiótica. Tradução José Teixeira Coelho Neto. São Paulo: Perspectiva, 2000.

PRENSKY, Marc. Digital natives, digital immigrants. On the Horizon (MCB University Press), [s. l.], v. 9, n. 5, out. 2001.

PRETTO, Nelson. Redes colaborativas, ética hacker e educação. Educação em Revista, [s. l.], v. 26, n. 3, dez. 2010.

RIBEIRO, Ana Elisa. Escrever, hoje: palavra, imagem e tecnologias digitais na educação. São Paulo: Parábola, 2018.

SANTAELLA, Lúcia. Da cultura das mídias à cibercultura: o advento do pós-humano. Revista FAMECOS, [s. l.], n. 22, dez. 2003.

SOARES, Magda. Alfabetização e letramento: caminhos e descaminhos. Revista Pátio, [s. l.], v. 29, 2004.

SOARES, Magda. Novas práticas de leitura e escrita: letramento na cibercultura. Educação \& Sociedade, [s. l.], v. 23, n. 81, p.143-160, dez. 2002. 